\title{
Leather Monitoring System Using Image Processing
}

\author{
Ruchika Argade $^{\# 1}$, Mayuri Dengale ${ }^{\# 2}$, Snehal Jagtap ${ }^{\# 3}$, Prof Patharwalkar Shilpa s ${ }^{* 4}$ \\ \#* Department of Electronics and Telecommunication, PGMCOE University of Pune, Maharashtra, India \\ *4 Assistant Professor, PGMCOE
}

\begin{abstract}
The purpose of this project is to design the system which monitors the various parameter about the leather e.g. area, pattern and cut or hole detection in the leather.

Leather is placed on conveyor belt fixing the background color of belt and then area of the irregular shaped leather is calculated using image processing and $2^{\text {nd }}$ case is if leather is regular or fix shaped then its pattern and whatever cuts or holes on the plane surface is detected using image processing only.
\end{abstract}

Keyword: Conveyor belt, Gray scale, Binary image, Pattern

\section{INTRODUCTION}

Leather is durable and flexible material created by the tanning of the animal rawhide and skin,often cattle hide.It can be produced through manufacturing processes ranging from cottage industry.It is producted in a wide variety of type and styles and is decorated by a wide range of techniques

.So in this paper we are presenting that how the area of irregular shaped leather can be calculated and the pattern and cuts can be detected on regular shape of leather using image processing technique as in [2].

\section{Production Process Of Leather}

The leather manufacturing process is divided into three fundamental sub-processes: preparatory stages, tanning, and crusting. All true leathers will undergo these sub-processes. A further sub-process, surface coating can be added into the leather process sequence, but not all leathers receive surface treatment.

PREPARATORY STAGES

The preparatory stages are when the hide/skin is prepared for tanning. Preparatory stages may include: preservation,soaking, liming, unhairing,fleshing, splitting,reliming, deliming, bating, degreasing,frizing, bleachin $\mathrm{g}$, pickling, and depickling.

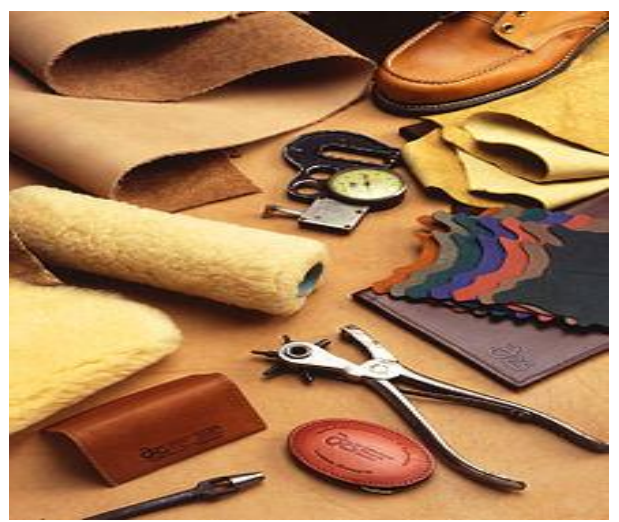

Fig 1.Leather materials

\section{TANNING}

It is the process which matches the protein of the raw hide or skin into a stable material which will not putrefy and is suitable for a wide variety of end applications. Many different tanning methods and materials can be used; the choice is ultimately dependent on the end application of the leather as in [4].

\section{CRUSTING}

It is the process by which the hide/skin is thinned, retanned, and lubricated. Often a coloring operation is included in the crusting subprocess. The chemicals added during crusting must be fixed in place. The culmination of the crusting subprocess is the drying and softening operations. For some leathers, a surface coating is applied. Tanners refer to this as finishing. Finishing operations may include: oiling, brushing, padding, impregnation, 
buffing, spraying, rollercoating, curtaincoating, polishing, plating, embossing, ironing, ironing/combing (for hair-on), glazing, and tumbling as in [7].

\section{A.Pinwheel Mechanism}

\section{WORK IN PAST}

This method consist of rollers having distance between centres of two wheels about $25 \mathrm{~mm}$. These wheels contain blunt pins on their rims which can drop into the grooves of the driving roller.

The leather is fed over the driving roller which, in turn prevents the pin dropping into the groove as in [6].

This action through a complex series of wheels and steel tapes attached to levers transmits the movement to a dial gauge which records the area of the leather.

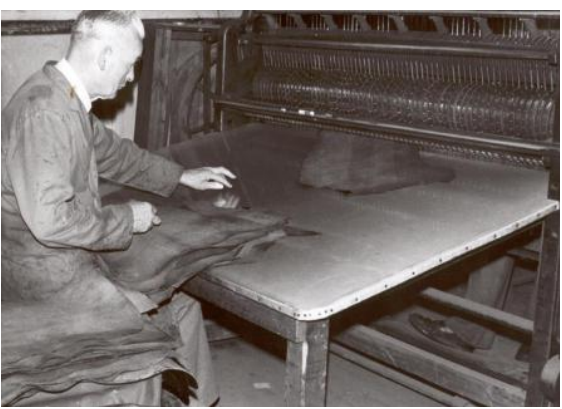

Fig 2.Pinwheel Mechanism

\section{B Roller Planimeter}

Roller Planimeter are commonly used for computing the area of the leather sheet in the leather industry. Roller Planimeter are attached to the wheels that allowed unlimited horizontal travel and vertical travel within the limits of arm movement. Unlike Pinwheel mechanism it is not "Pinned"down to work area.Roller Planimeters can roll all over the place without the restriction of an attached base.

The popular Roller Planimeter are more economical for leather area measurement.

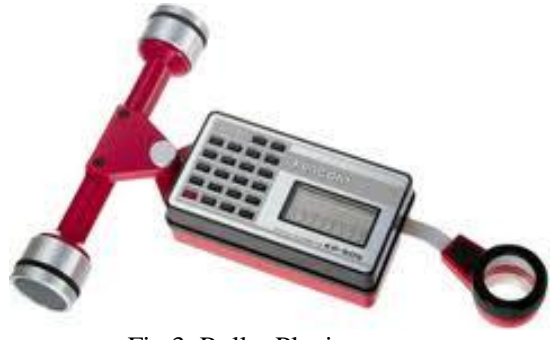

Fig 3. Roller Planimeter

\section{BASIC WORKING PRINCIPLE}

In prerequisite we are going to calibrate that what is the value of one pixel in the image taken from the particular fixed height of camera.

Leather piece placed on conveyor belt when comes under the camera section then belt will stop and then camera will take picture of that piece and separates the foreground and background of the image. Then the background of the image which we are going to fix with white color is separated or removed and the remaining part is taken in consideration for the calculation of the area .

According to previous calibration the area of that piece is calculated.

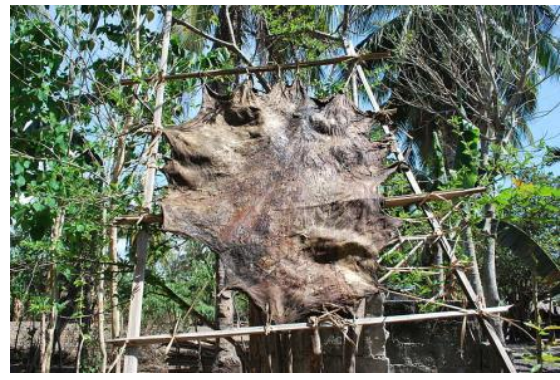

Fig 4.Example of leather crusting 
In $2^{\text {nd }}$ case there we will fix the shape of leather and then according to that there cuts or holes on the leather will be detected.

In case of pattern recognization that can be possible with any shape.

After getting the picture the pc will send command and the conveyor belt will start again.

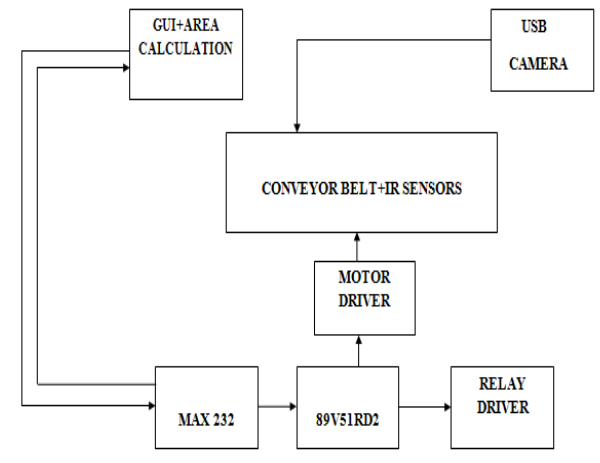

Fig 5.Entire assembly of Leather monitoring system

As shown in fig 4 the leather is dried and so it can have any undesired shape so it is difficult to get the area of that leather. So we have designed this system.

\section{FLOWCHART:-}

Flowchart of area calculation of leather given below:

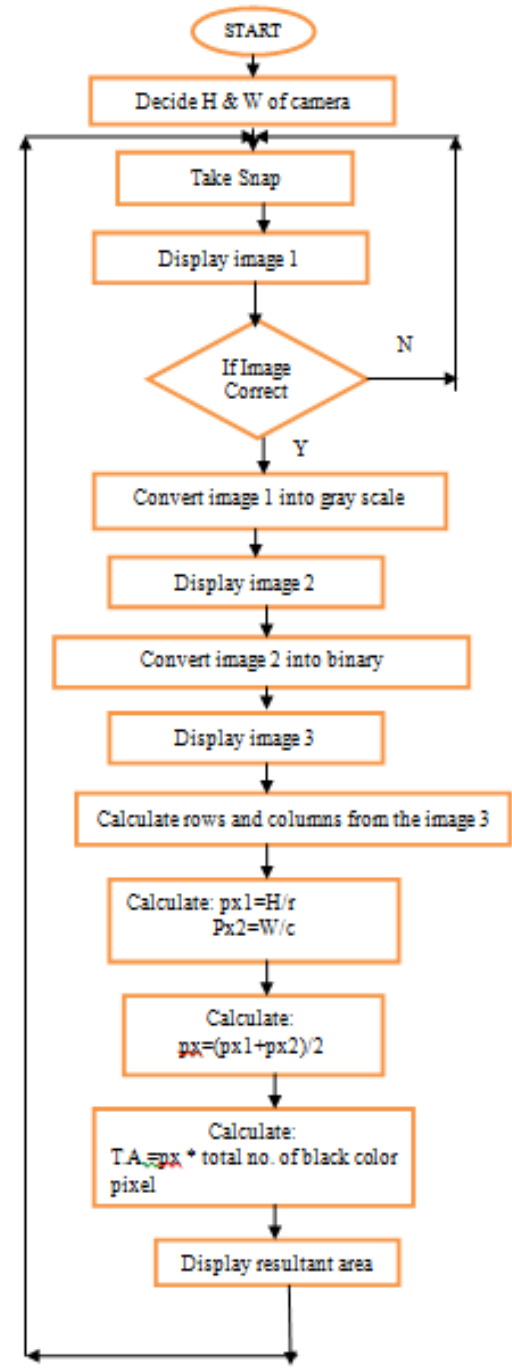


Terms used in Flowchart:-

1. H- Height of camera from conveyor belt

2. W-Width of the conveyor belt

3. r-Rows

4. c-Columns

5. T.A.-Total Area

\section{In the foot ware industries and bags:-}

\section{ApPlication}

The leather area measurement and monitoring the quality of the leather makes influence on the buiseness of the particular section.

\section{Other than the leather material:-} is useful.

In the pattern making of the different materials' the area measurement and the pattern reorganization system

\section{RESULT}

This method results in high accuracy area measurement of the leather. Without contact the automatic surface area of the leather sheet is calculated. This method doesn't neglect any part of the area of the leather sheet.

\section{CONCLUSION}

In above mentioned systems the area is calculated by counting number square which the leather sheet occupies and multiplies it by the known area of a square to achieve the approximate complete surface area of the leather sheet.

Experimental results show that due to the irregular edges both the above method results in error ranging between 15 to $20 \%$.

\section{ACKNOWLEDGMENT}

This is to acknowledge the indispensible support and Contribution of Prof. Shilpa Patharwalkar and Prof. Rajesh Halke in this article. Without the advice, recommendations and motivation of both of them, this paper would not have been possible.

Mr. B. Barker, "Photographs by $\quad$ Enid Sheldon from the
1980's,"http://www.otley.co.uk/gallery/sheldon/industries/leather/index.htm,24 May. 2008.

[2] J.W. Kwon; Y.Y. Choo; H.H. Choi; J.M. Cho; G.S. KiI,“Development of leather quality discrimination system by texture analysis”, TENCON 2004. 2004 IEEE Region 10 Conference pp.327- 330 Vol. 1, 21-24 Nov. 2004.

[3] R. Muhammad, F. Faizan, M. Shoaib, T. Qadri "Irregular surface area measuring instrument" in 2nd International Conference on Education Technology and Computer, v 1, p V156-V159, June 22- 24.

[4] Yi, J., Wang, D., Zhou, J. “Impact of box ratio and pinwheel pattern on the pallet loading problem” Journal of Southeast University pp. 267-270, 2009

[5] K. Zojiro; F. Yasuaki; N. Yoshio; T. Yoshinori; T. Mamoru; Y. Shin "A Study on Approach Speeds of the Hands under Metal Press Machine Operation" in 45th Conference the Human Factors and Ergonomics Society pp, 1119-1122, 2001.

[6] Anon, "Linear Motion Systems," Industrial Lubrication andTribology, Vol.46, No.6, pp.12-21. 1994.

[7] Shim, H. Kochem, M. Tomizuka, M. "Use of Accelerometer for Precision Motion Control of Linear Motor Driven Positioning System" in Proceedings of the 24th Annual Conference of the IEEE Industrial Electronics Society, 1998. IECON '98 2409 - 2414 vol.4, 31 Aug-04 Sep 1998. 